\title{
JONATHAS DE ANDRADE: ARTE TECENDO MEMÓRIAS NA INTERFACE RURAL-URBANO BRASILEIRA
}

\author{
Claudia Ribeiro ${ }^{1}$
}

\section{Introdução}

Atualmente empenho-me em aprofundar a compreensão das relações humanas com o seu meio, por intermédio do estudo da trajeção de uma paisagem ${ }^{2}$. Faço isso em movimento que passa por estudos etnográficos ligados a apreensões imagéticas, por certo em alguma conexão a reflexões antropológicas. Percurso de investigação que, por conta de meu particular tema de exploração - a percepção da paisagem no contexto de estudos etnográficos de memória coletiva - acaba intrinsecamente mobilizando o viés estético. Porém em proximidade à apreciação crítica de um dado cenário brasileiro de conflito socioambiental, com suas próprias imbricações urbanas e rurais (Ribeiro, 2017).

O espaço delimitado por esse atual contexto de estudos interdisciplinares e por meu pessoal interesse pelo fazer artístico como via de libertação imaginativa contém os necessários pontos de ressonância que motivam essa contribuição: um misto de resenha e de entrevista sobre um determinado trabalho autoral artístico.

Se o primeiro contato que tenho com a obra desse alagoano que mora em Recife acontece por meu deambular por sua exposição - museu do homem do nordeste ${ }^{3}$ minha mobilização sensitiva maior acontece quando conheço uma de suas mais recentes obras, em mostra pública pela primeira vez na $32^{\text {a }}$ Bienal de São Paulo ${ }^{4}$.

Nessa mostra que girou em torno da Incerteza Viva a obra de Jonathas metaforicamente tensiona o limite vital, em metafórico entrelaçamento de duas espécies - pescadores artesanais do nordeste brasileiro e os peixes capturados em seu cotidiano de trabalho. Em resposta que aceita o desafio temático da mostra na abrangência de sua intenção ético-política: a provocação por um propositivo repensar

\footnotetext{
${ }^{1}$ Universidade Federal do Rio Grande do Sul, Brasil.

${ }^{2}$ Trajeção é o neologismo proposto por Augustin Berque (2011: 188; 193 e 194), no conjunto mais abrangente de seus estudos da mediância - uma propriedade dos meios. Tal termo nomina o movimento de contínua interação entre os mundos objetivos e subjetivos, que constitui a realidade dos nossos meios, inseridos esses no conjunto mais abrangente da ecúmena - a parte habitada da Terra.

${ }^{3}$ Museu de Arte do Rio de Janeiro (MAR), dezembro de 2014 a março de 2015, Rio de Janeiro.

${ }^{4}$ Pavilhão Cicillo Matarazzo, setembro a dezembro de 2016, São Paulo.
} 
sobre a "violência do pensamento moderno", em incursão por terrenos não conhecidos só franqueados pelo fazer imaginativo (Silva, 2016: 58).

\section{O Peixe}

Partindo da memória correspondente ao que já havia visto na exposição no MAR, com posteriores adições de novas informações obtidas em pesquisa de material catalográfico, realizo o conjunto de consistente e reconhecida produção do artista, materializada em seleções e efetivas participações em convocatórias, exposições e residências, tanto no Brasil como no exterior. (Andrade, 2012a; 2017).

Jonathas nasceu em 1982 em Alagoas, sendo que atualmente vive e trabalha em Recife, em um ateliê-casa que divide desde 2006 com outros artistas. Formado em Comunicação Social, inicia sua exploração artística em 2007, com educação para adultos, que surge a partir de resquícios que ele coleta por ocasião da aposentadoria de sua mãe - cartazes que ela utilizava na alfabetização de adultos em seu trabalho como professora pública de Recife. Utilizando esse material como matriz e seguindo, em suas exatas palavras, "os fôlegos utópicos enraizados nos métodos de Paulo Freire", enceta conversas e produção fotográfica em estreito trabalho com um pequeno grupo de mulheres não alfabetizadas, no bairro de Casa Amarela em Recife. As conversas viram pautas fotográficas para cartazes que ele então produz, alimentando posteriormente conversas em novos encontros. A instalação final mistura os cartazes novos e velhos, em processo no qual ele diz perceber um achatamento histórico, no entanto não invisibilizando um sentimento de intensa revolta ao longo de todo o percurso. Revolta que ele continua ecoando, em sucessivas elaborações imagéticas de paulatina complexificação temática e construtiva, intensificando essa proximidade a essas vozes anônimas, situadas nas margens da interface rural-urbana brasileira (MAR, 2015; PIPA, 2011).

Assisto em outubro $O$ Peixe, filme de 39 minutos, realizado em $16 \mathrm{~mm} \mathrm{e}$ posteriormente transferido para meio digital. A apresentação dá-se em um ambiente de semiobscuridade, que progride em direção à tela. Não há cortina, porta ou qualquer outra barreira para abrigar o semicírculo de paredes que no seu fundo abriga a tela de projeção, o espaço de aconchego criado para a contínua exibição da obra. Espaço que é constituído por piso acarpetado à frente da grande tela, delimitado por alguns cubos, a 
guisa de bancos e tênue fronteira com o ambiente de circulação no térreo do prédio de três pavimentos. Meio não muito distante da entrada do monumental espaço expositivo: o "Pavilhão da Bienal" como popularmente é conhecido, majestosa arquitetura de Oscar Niemayer que desde 1957 abriga as sucessivas edições desse imenso empreendimento artístico, por sua vez inserido nos cerca de 150 hectares do Parque do Ibirapuera, coração verde da capital paulista. Como acontece nesses casos, as pessoas chegam em um ponto da projeção que não sabem bem qual é. Eu fico e assisto um ciclo completo, e depois mais uma vez. Nesse percurso, noto como eu, e também as pessoas que chegam, intuitivamente fogem da claridade do salão vizinho. Desse modo buscam, além de certo conforto na acomodação física do corpo, a escuridão, para melhor distinção da imagem. Uma procura que, em alguns casos, leva as pessoas quase até a borda da tela, buscando maior proximidade com as imagens que vão sucessivamente passando - sem palavras de nenhuma espécie, com incidências musicais sutis, que apenas modulam a robustez narrativa da sequência de imagens filmadas (Peixe, 2016).

Como detalha o respectivo afiche explicativo junto à entrada do espaço expositivo, nessa obra o autor acompanha filmicamente uma série de pescadores nas paisagens do litoral nordestino brasileiro. Contudo, com uma intenção anterior ao ato artístico por si só. Ele propõe a esses homens que logo após a captura de um peixe, o animal seja liberado do artefato que o capturou (uma rede, arpão ou anzol) para que, em ato contínuo, fosse abraçado junto ao peito desses homens. O que o filme mostra, a partir disso, é esse encontro carne a carne: o animal, ferido e fora d'água - logo, no seu debater agônico, contido pelos braços na parte superior do corpo desses pescadores, nesse abraço que perdura até o último sinal vital do peixe aprisionado. No filme, esse momento limite da vida que se esvai é denunciado pelos olhares envolvidos, em uma dezena de histórias nas quais são aproximados esses homens e suas presas.

Aparentemente as mesmas, mas todas diversas. Jonathas de Andrade cita os primeiros nomes dos vários outros homens que aceitaram seu convite - Menezes, Ciço, Cipriano, Irmão, Leno, Xau, Curió, Keno, Rom e Ronaldo, que em seu cotidiano de pesca nas cidades de Piaçabu e Coruripe, na foz do Rio São Francisco, capturam Pirarucus, Tambuacus e Tilápias. A demarcação do lugar de registro dessa paisagem, para quem conhece o nordeste brasileiro é clara: lugar em que o rio vira mar, que entendo pela alternância das tomadas mais fechadas feitas nos meandros dos mangues, com os planos mais amplos que mostram a linha crivada de coqueiros do litoral. Os 
homens aparecem naturalizados nessa paisagem de notas edênicas, tenuamente historicizada, no que penso ser a deliberada intenção do viés artístico perseguido.

Em aceno indicativo da obra, disponho a seguir uma foto do ambiente de projeção na Bienal e uma sequência de stills que realizo no dia em que assisto ao vídeo.

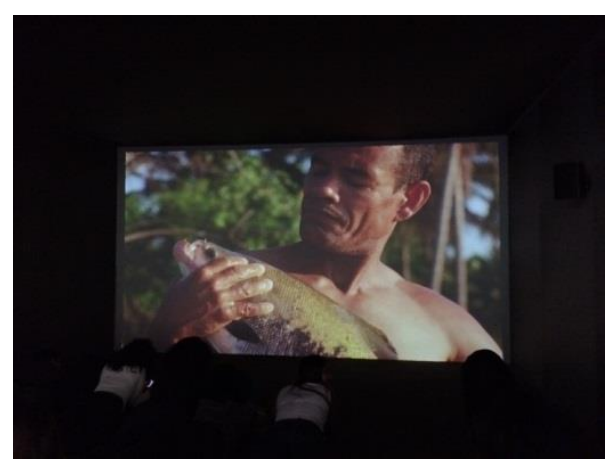

Figura 1: sala de projeção.

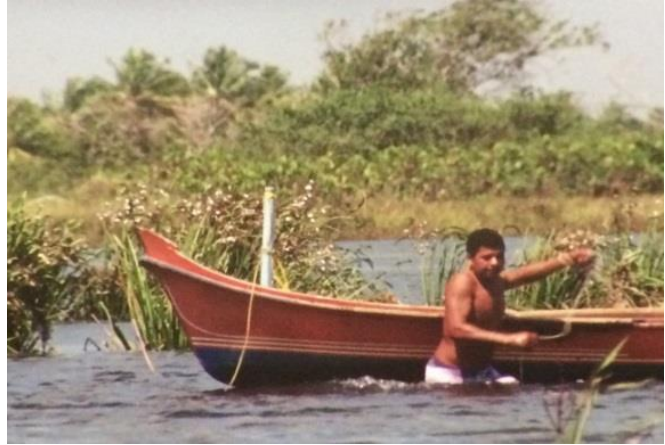

Figura 2: still 1 O Peixe.

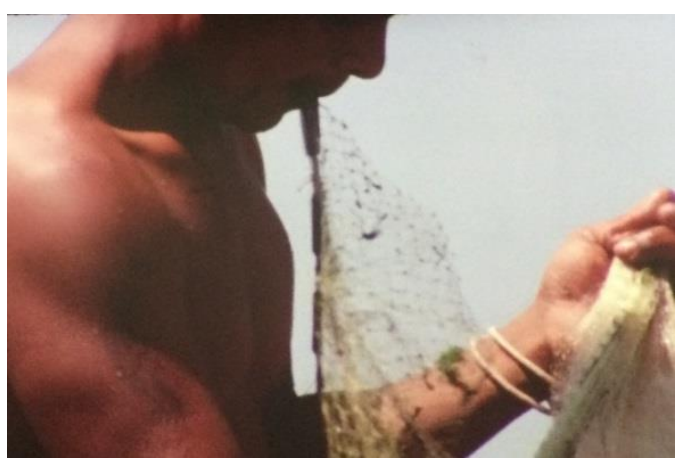

Figura 4: still 3 O Peixe.

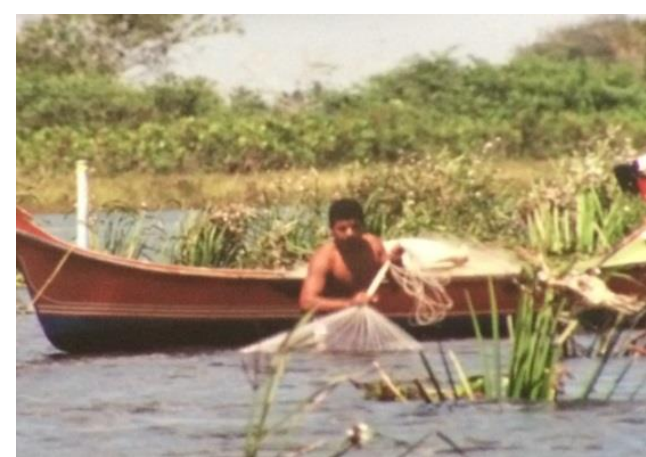

Figura 3: still 2 O Peixe.

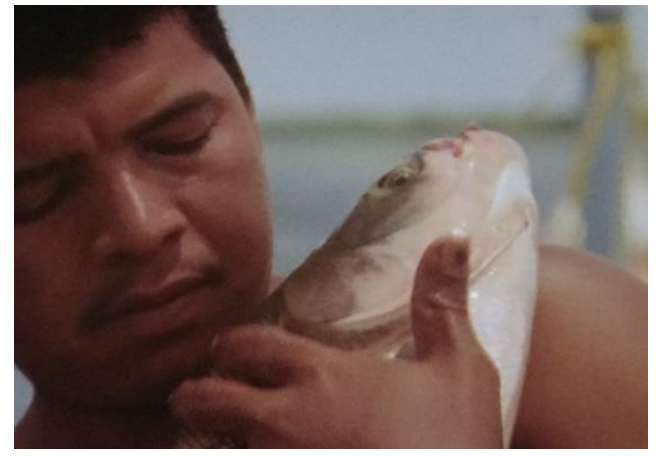

Figura 4: still 4 O Peixe. 


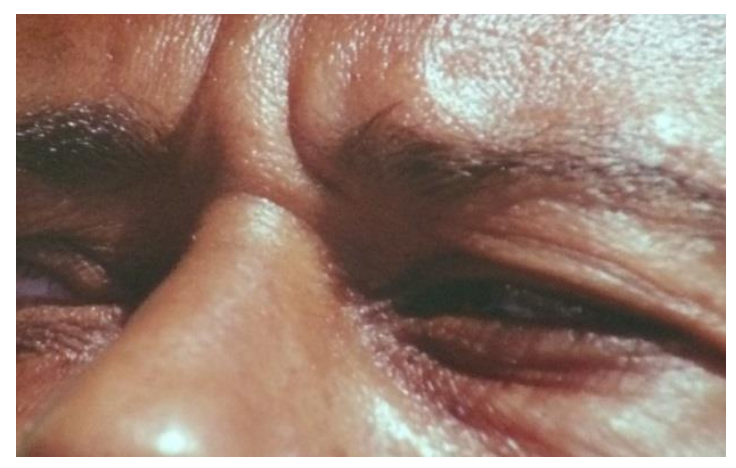

Figura 3: still 5 O Peixe.

Fontes de todas as figuras: Claudia Ribeiro (2016), São Paulo.

\section{Uma conversa}

Resolvo ceder às minhas fortes impressões e às intuições que delas resultam e decido tentar falar com Jonathas: envio-lhe um e-mail, onde me apresento e explico-lhe sobre o contexto de meu interesse por sua obra, bem como da vontade de escrever algo sobre essa experiência. Recebo descomplicada e gentil resposta. A qual abre espaço para um diálogo que acontece em algumas etapas, ao longo do qual fui colocando alguns pontos de possível reflexão, como passo a expor.

Relato que pedi que ele reflexivamente comentasse o conjunto de sua obra e de suas motivações imediatas, com enfoque especial no vídeo $O$ Peixe.

Sugeri igualmente que fosse explorado, pois intui importante, sua inserção na cidade em que vive. Nisso fazendo parte o contexto de sua inspiração junto à obra de Gilberto Freyre.

Bem como indiquei de ponto de possível ampliação a respeito do engajamento que ele declara perseguir: o esclarecimento das lutas de conservação de memória, em seus randômicos - mas históricos - processos de escolha, nesse limiar frágil entre o sensível e o possível de ser atingido pela materialização artística.

Especificamente sobre essa figuração artística com esses peixes e homens, expliquei que gostaria de entender um pouco mais sobre essas pessoas e peixes: esses seres atraíram o artista para essa paisagem - e não para qualquer outra. Esses homens adultos, de várias idades e esses grandes peixes - homens e peixes, todos muito bonitos, impossível não reparar. 
De que gostaria de saber quem são esses pescadores e de como acontece o contato do artista com essas pessoas, da mesma forma expressando minha curiosidade em saber sobre as formas de aproximação e relacionamento com outras comunidades que são mobilizadas em suas obras.

Desse jeito em vários momentos vamos articulando os contornos dessa troca, que dá resultado a um significativo comentário, em áudios que Jonathas me envia em 24 de novembro de 2016. Material que é transcrito e substancialmente a seguir integra essa publicação - que ele preferiu que fosse uma construção de autoria única (ANDRADE, 2016).

\section{Jonathas de Andrade fala sobre o conjunto de seu trabalho}

O projeto do Peixe foi pensado há vários anos, como outras ideias que eu já tive, que vou realizando na hora em que elas vão ficando urgentes. Várias foram assim: as carroças, o 40 nego bom é um real... Projetos que comecaram individualmente, e depois acabaram se reunindo, em torno do museu do homem do nordeste. Que é um museu... que tem o mesmo nome de um museu criado por Gilberto Freyre em $1979^{5}$, mas que passei a criar como um duplo, através desses vários projetos.

Eu sempre ia lá e me surpreendia com o que era um Museu Antropológico, com artefatos, e tal... Mas a minha surpresa maior estava em ver que ele não dava conta exatamente de revisar criticamente a história... a história de colonialismo do lugar, a história do lugar do trabalho, do lugar da raça, do racismo, da questão de classe... que são assuntos que me interessam.

Então eu achei que esses (meus) projetos podiam tensionar historicamente essas questões, mas em estreita ligação com a história do Museu, com a história dos escritos do Gilberto Freyre... Uma das minhas primeiras estratégias foi levar o título a risca... quase como se fosse um museu do homem - da masculinidade - do nordeste. Estratégia que coloca a ironia, um ceticismo no título, falando um pouco também sobre o machismo da região - através de um homoerotismo, que é um ponto que você aborda rapidamente, quando você comenta sobre O Peixe.

Uma das coisas que eu acho interessante nos seus escritos de Gilberto (Freyre) é o seu jeito apaixonado quando ele fala sobre a sensualidade, a sexualidade, e de como esse aspecto teve um papel fundamental na criação da mescla, da miscigenação, do brasileiro, do Brasil. E aí eu pensava que se a sensualidade, se esse certo erotismo fazia tão parte daquela cultura, eu achei que aquilo não deveria ser um assunto, mas deveria ser parte de uma metodologia.

E isso acontece muito no projeto dos cartazes (educação para adultos) - isso está presente de uma maneira geral como um elemento de tensão ali. Por que eu acho que a sexualidade é uma espécie também de tabu social, na medida em que é também um poder. Mas é também um dos motivos de exotização do Brasil, inclusive lá fora. Então acho interessante como isso permeia entre o poder e a moralidade. E aí eu achava que, aquilo, ao invés de virar um assunto, era mais interessante como uma temperatura para os projetos. No projeto dos cartazes essa questão permeia a relação que está sendo colocada ali: na autoimagem, na criação da imagem do outro, de como isso vai para a imagem sobre uma região e também para a imagem do Museu - há uma série de proibidos que passam por aí.

No projeto das carroças, menos, eu penso - a tônica ali é outra. Eu ficava fascinado como eu sentia as carroças como que fazendo parte da paisagem visual da cidade, da

\footnotetext{
${ }^{5}$ Museu do Homem do Nordeste, Recife.
} 
paisagem sonora da cidade. Eu gostava de pensar que aquilo não era só o sinal de uma vida lascada, de uma marginalidade. Mas que aquilo era uma quase como um eco da vida rural, da presença do campo no meio da cidade. E eu gostava de pensar... que legal seria uma cidade que incorporasse aquilo, reconhecendo o poder dessa presença, reconhecendo os cidadãos que fazem parte desse acontecimento cidadãos que também fazem parte da cultura do lugar...

Mas, evidentemente, o que existe não é isso - o que existe é uma cidade cujo entendimento oficial é super truculento. A cidade estava criando leis... melhor dizendo, o governo estava criando leis que autorizassem - através do entendimento de maus tratos aos animais - a remoção das carroças para o interior. Uma lei absolutamente cínica, por que se a questão fosse realmente sobre os maus tratos, seria o caso de ser ter medidas educativas, ou... em outra linha, multas, coisas assim. Mas na verdade, a lei autorizava a remoção para o interior, onde os supostos maus tratos iam continuar. Então era a história de um cinismo que me incomodava muito. E aí eu imaginava... caramba... quando de vez em quando via uma carroça, imaginava que, se ao invés dessa imagem pulverizada, se fosse possível imaginá-las arrancando no meio do centro, juntas, todas juntas de uma vez só. Tanto a invisibilidade seria impossível, quanto passaria a existir uma imagem de uma força poética, linda assim... Porque era outra imagem que me vinha, com muito poder, com muita forca, brincadeira, felicidade... muita algazarra. E foi dessa forma que o projeto foi começando a ganhar corpo. Foi desse modo que eu entendi que o projeto tinha forca. A articulação acontece por esse filme que ia ser gravado, que tinha uma cena que era uma corrida de carroças... e aí, entendido como ficção, o projeto foi acontecendo. E eu achava muito curioso de como é que a ficção possibilitava aquilo tudo - pois, na verdade, tanto a corrida ia acontecer de fato, quanto era muito real que os carroceiros estavam na cidade.

Em o 40 nego bom, a tônica de início é de outra ordem, tem certo erotismo masculino ali tensionando outra trama. Através de uma convocatória eu convido trabalhadores para posar para mim no estúdio, e a partir disso também trabalho com trabalhadores do campo mesmo, a gente que realmente faz o doce... e aí crio aquela colagem de imagens. São fotografias em seu original, mas que vira uma grande colagem, que se transformam em uma serigrafia sobre madeira, criando aquela estória que é... aquela fábrica de doces. O título 40 nego bom um real fala... do jeito de ser vendido o doce nos mercados, mas também expõe uma matemática de outra espécie - sobre como o trabalho barato é uma coisa abundante, super naturalizada, e de como o negro está muito vinculado a esse lugar da exploração, da servidão.

\subsection{Sobre $O$ Peixe}

Mais recente, essa experiência já é outra... super forte... a resposta está sendo super emocional das pessoas. É um dos poucos trabalhos meus que tem... silêncio. Eu sou muito do texto, mas aqui é mais uma imagem que passa uma sensação. E estou adorando a força de comunicação de um projeto como esse.

Eu imaginava essa situação dentro desses vários pensamentos do museu do homem do nordeste... de uma tradição de um rito quase inventado, mas que fosse super possível, plausível... um rito que seja possível no seu seu olhar para aquela imagem, pois ela cola com uma expectativa que a gente tem. Uma ideia romântica muito centrada em quem vive na cidade - em quem vive toda uma crise, meio essa culpa de explorar o planeta, de explorar os recursos naturais, e ao mesmo tempo de ter as benesses disso, todas concentradas nessas cidades, mas com enormes consequências para a natureza. Essa imagem, tanto fala sobre do incrível da existência de uma comunidade que respeita os animais, mas também fala de uma inviabilidade disso.

Aquela imagem - aquela cena - ela é um abraço, mas é um abraço de dominação, um abraço mortal, de uma inevitabilidade dessa relação - de uma inevitabilidade de uma relação de poder. É uma imagem de carinho, de afeto, mas é uma imagem de extrema violência, também, de dominação. É um sufocamento, uma imagem que é 
um abraço mortal. Fica exposta assim a ambiguidade dessa imagem: nesse poder e nessa força poética. Nessa ambiguidade entre um carinho, um respeito, uma despedida... e também nessa morte que está ali. O projeto tem uma estrutura de loop, pois era a forma da repetição ritual existir - o filme também era uma forma do ritual existir, já que ele acontece na repetição.

Também para mim é importante mencionar a experiência de corpo que existe ali. Eu ficava pensando que os pescadores fazem isso todos os dias - pescam e depois jogam o peixe lá (no barco). Então, se eles têm muita intimidade com o bicho, ao mesmo tempo desenvolvem uma coisa muito automática para eles... Por outro lado, também tem uma coisa natural, de uma naturalidade com a morte mesmo, como parte do trabalho, da vida, e tal. Então fiquei curioso como isso poderia ser uma experiência de corpo pra eles, que iam fazer a cena, propondo uma alteração básica, mas muito forte ali: ...quero que você abrace o peixe e espere ele morrer. E veja... assim... acompanhe essa passagem para morte...

Isso tudo acontece sem ensaios: a primeira vez que acontece é para câmera, então, com isso, sim, existe uma coisa documental ali - é uma ficção relativa, é uma ficção documental. Pois a cena é real, nessa hora vira muito documental mesmo. É ficção, por que o ritual não existe, mas é documental por que aquela cena está acontecendo ali pela primeira vez.

E cada pescador reage de um jeito. Têm uns que atuam mais, tem uns que entram completamente na vibração da cena, do peixe, se emocionam, e se concentram no que está acontecendo. A câmera quase desaparece... Muito bonito, foi muito forte para mim também - tanto por eu ter colocado os elementos para que esse encontro acontecesse - inventando essa cena, propondo essa cena - como por gravá-la.

Essa cena é muito forte, gravar a cena era muito forte. Então, para mim era também importante não fazer ela muitas vezes. Eu gravei em $16 \mathrm{~mm}$ e isso deixa muito restrito o tanto de material gravado que a gente podia ter. Com isso, eu gravava uma ou duas vezes cada cena, não podia fazer muito mais. E claro, cada vez que isso acontecia, o peixe também sofria - um peixe morria. Então isso foi uma das várias coisas de cuidado no projeto.

Então... por essa intimidade que os pescadores têm com o peixe, a cena, embora fosse uma coisa imaginada, requisitava um repertório corporal dos pescadores, que é o que faz a coisa ter uma naturalidade. Eu imaginava que eles não iriam pensar no jeito de pegar o peixe... eles (os seres) respondem-se corporalmente um à presença do outro. E isso poeticamente eu acho muito forte também.

O pescador ele é tratado como aquele ser solitário que está ali... mas quando ele encontra outro ser - ali já são dois seres, são duas espécies em encontro. Mas esse encontro é uma despedida e é uma morte: é uma espécie que domina a outra. E logo o pescador volta a ser sozinho: existe uma devoração real nesse momento.

Além disso, outra relação desse tipo acontece na relação da câmera com o pescador - pois a câmara também devora essa coisa dos corpos em relação - a relação do peixe com o pescador. Reproduzindo, sim, essa sensualidade, esse amor, mas também sendo uma relação mortal, uma relação que sufoca, que aprisiona...

\subsection{Sobre a participação das pessoas nos projetos}

Nesse caso do Peixe eu tive uma equipe de cinema envolvida. Então a gente pode fazer algumas visitas antes, quando eu explicava que eu estava fazendo... que eu estava fazendo um filme, que era a história de um pescador que abraçava os peixes na hora em que os pescava. E perguntava se eles topavam me ajudar a fazer esse filme. Então era dessa maneira pela qual a coisa iniciava. Eles já tinham um entendimento que seria uma representação de uma coisa... mas que seria uma representação de uma cena, de uma situação de um pescador. Então eles só precisavam ser eles mesmos, mas criando o acontecimento que me interessava. Sendo dessa forma, um processo com uma equipe de cinema, eu pude sair de onde eu geralmente fico - cuidando da produção, cuidando da câmara e tal - para me 
dedicar a conversar mais de perto com eles. Isso foi muito bom. Minha ideia agora é voltar, logo em seguida, e apresentar o filme na praça. Uma oportunidade de trocar com eles, ver como é que foi essa experiência para eles... Eu acho que vai ser boa essa troca.

No projeto das carroças o ponto de partida foi um planfeto. Eu ia às feiras de troca de cavalo e de materiais de cavalo e conversava com eles, eu e a equipe. Eu tinha alguns amigos que estavam fazendo um filme sobre uma procissão de cavalos que acontece anualmente - uma procissão de cavaleiros, com carroças, famílias, e tal. Então as pessoas já reconheciam esses meus amigos e isso deu a credibilidade para mim e a equipe - e para o projeto.

Ao seu final eu fiz uma exibição no cinema São Luiz - que é o cinema antigo, central, da cidade de Recife. Como no início do projeto, panfletei também sobre isso. Mas como era meio de semana, muitos deles não puderam vir, mas ainda assim algumas pessoas das carroças viram o filme, foi muito legal. Como O Peixe foi filmado em Piaçabuçu e Cururipe, que são cidades menores do interior, eu acho que realmente a gente vai conseguir mostrar o filme para as famílias e pra cidade. Eu acho que vai ser um processo legal. Mas esse retorno ele depende de cada projeto, sabe? No projeto dos cartazes, eu, por exemplo, fazia trocas com as pessoas que participaram - eu devolvia fotografias do encontro, algumas fotografias que eu tinha tirado dos participantes.

\section{Faço um convite}

Decididamente a estratégia de construção da narrativa que em $O$ Peixe é escolhida faz acontecer um evento, "[...] um fato último para a consciência sensível [...]" (Whitehead, 2006: 52). Fica claro que essa obra contém um especial contexto inventivo, em ato com certeza performático. E ao longo dessa visual reconstrução o autor utiliza o que poderia ser descrito por Claudine de France (1998: 198) como a etnográfica e simples estratégia da cadeia: “[...] esse modo de articulação direta que é o contato necessário, ou obrigatório, entre os homens ou os elementos do dispositivo, entre uns e outros, para que o processo possa se desenrolar [...]". Contudo, em direção e proporções inusitadas. Nesse abraço que é por ele proposto para ser realizado por esses pescadores que passam integrar o seu filme, o autor não só introduz um elemento novo nesse cotidiano da pesca, mas comprime - de maneira dramática - os seus elementos.

Nessa nova forma, a imaginação consegue artisticamente subverter uma relação que poderia ser apenas entendida como utilitária e predatória entre entes naturais. Em um processo que então passa, em sua singularidade, a constituir a memória dessa paisagem. Propondo novas aberturas para pensar sobre a perspectiva de duração do e no mundo, posso ver na imagem do filme uma trama, que eu rememoro quando aqui escrevo sobre o que retive do que assisti na ficção documental de O Peixe: raízes, arpões, roupas, troncos, celulares, galhos, barcos, remédios, iscas, redes, humanos, linhas, dinheiros, máscaras, águas, peixes, combustíveis, anzóis, folhas, caniço e rádios, 
em entrelaçamento de muitas "coisas", diversas e também únicas. Dúvidas dessa reconstrução aparecem - em alguns pontos, não sei mais se conto o que vi, ou o que penso ou sinto que também possa estar contido no que foi enfim montado como filme.

Ficam como reais pensamentos as possibilidades de tessituras que para mim aparecem, como conexões, em cruzamentos de linhas-circulações nesses vários lugares de paisagens. Paisagens marinhas brasileiras, nesse caso indubitavelmente nordestinas, vistas pelas vias do trabalho de parte de sua população. Pois alguns seres humanos (não somente homens, diga-se de passagem) também (e ainda) pescam para proverem sua vida com vários alimentos: posso imaginar que esse humano não integra essa paisagem só por causa desse peixe.

Está posta a existência de pontos de tangenciamento entre o exercício do campo antropológico (e mesmo, em abrangência maior, com a prática das ciências sociais aplicadas) com os procedimentos e efeitos associados ao conjunto da obra artística de Jonathas de Andrade. Pois os dois movimentos, além de por óbvio poderem compartilhar um recorte empírico e temático de exploração, transitam em uma mesma área de desvelar subjetivo. Área por onde livremente caminha a exploração poética, por onde, no entanto, nem sempre passa o artesanato (ou a arte) do fazer antropológico e etnográfico ${ }^{6}$.

Fica, pois, um convite para futuros aprofundamentos, igualmente endereçado às práticas científicas e artísticas sociopoliticamente situadas. Nada mais providencial, em tempos de reformismos reducionistas de toda sorte, a obrigação de revisão crítica e teórica que Jonathas de Andrade instaura, quando coloca com clareza e despudor as referências que fazem parte da motivação de suas práticas, bem como quando se apropria e utiliza termos que tem outros significados em contextos distintos do que o artístico.

Sobre a materialização de suas autorais práticas, penso que transpõem o marco local - cujo atingimento já seria muito significativo. Mas não por intermédio de eventos de qualquer espécie, mas sim por atos que poética e sensivelmente colocam em relevo a voz de quem está às margens do discurso do desenvolvimento: em um contexto urbano brasileiro, mas em direta conexão com as origens que vem de sua ruralidade. A transformação do semblante dos homens ao final dessa luta de vida e de morte,

\footnotetext{
${ }^{6}$ Esse comparativo (e extensa reflexão sobre os enleios da prática etnográfica e antropológica, em desenvolvimento que aqui não cabe) pode ser encontrado em Ingold (2011: 229-243).
} 
eternizada na construção videográfica de $O$ Peixe, acena para mim na direção do que explicam as textuais palavras de Jonathas, nessa feita sobre o Levante.

$\mathrm{O}$ rito abençoou a invisibilidade em uma existência celebratória. [...] no Recife proto-urbano de um Brasil supersubdesenvolvido [...] a arte foi o que possibilitou o nó que coloca em rede concretude e invisibilidade, marginalidade e celebração, impossibilidade e insurreição, ilegalidade e ficção. Foi a arte que desencadeou alguma coisa que era antes absolutamente incerta e bastante arriscada [...]. Aconteceu. (Andrade, 2012, versão livre minha do original em inglês).

Ponto, digo eu nesse momento.

\section{Referências}

ANDRADE, J. Future Generation Art Prize 2012 - Jonathas de Andrade, Brazil. 2012a. Vídeo disponível em: < https://www.youtube.com/watch?v=bjDK8GuWzY8 >.

Acesso em: 10 Nov. 2016. . Jonathas de Andrade 'O Levante'. (The Uprising) Horse drawn cart race in the centre of Recife. Blog of Centre For The Aesthethic Revolution. De La Barra, P. L. 2012b. . Áudios gravados em 24 Nov. 2016. 17 minutos. RIBEIRO, C. 2016. . Web site Jonathas de Andrade. 2017.

Disponível em: < http://cargocollective.com/jonathasdeandrade/Jonathas-de-Andrade >. Acesso em: 15 Jan 2017.

BERQUE, A. A ecúmena: medida terrestre do Homem, medida humana da Terra. Para uma problemática do mundo ambiente. In: SERRÃO, A. V. (Org.). Filosofia da Paisagem. Uma Antologia. Lisboa: Centro de Filosofia da Universidade de Lisboa, 2011. p.187-199.

FRANCE, C. Cinema e Antropologia. Campinas: Editora da UNICAMP, 1998.

INGOLD, T. Being Alive: essays on movement, knowledge and description. London, New York: Routledge, 2011.

MAR. Conversa de Galeria - Museu do Homem do Nordeste. Jonathas de Andrade, Clarissa Diniz e Paulo Herkenhoff., Rio de Janeiro, 2015. Disponível em:

< https://www.youtube.com/watch?v=_KCWNySwC4E >. Acesso em: 10 Nov. 2016.

O PEIXE. Direção Jonathas de Andrade. 32 ${ }^{a}$ Bienal de São Paulo. Incerteza Viva.

Produção Desvia e Wexner Center for the Arts. 39 minutos. Color. 16 mm. 2016.

Prêmio PIPA, P. Finalistas PIPA 2011: Jonathas de Andrade. 2011. Disponível em: < http://www.premiopipa.com/pag/artistas/jonathas-de-andrade/ > .

Acesso em: 10 Nov. 2016.

RIBEIRO, C. Delineando posicionamentos epistêmicos em torno de um estudo etnográfico de paisagem. Anais do I Colóquio Ibérico de Paisagem. O estudo e a construção da Paisagem como problema metodológico. (no prelo). Lisboa: Instituto de História Contemporânea da Faculdade de Ciências Sociais e Humanas da Universidade NOVA de Lisboa, 2017.

SILVA, D. F. Sobre diferença sem separabilidade. In: Fundação Bienal de São Paulo (Org.). Catálogo da 32 ${ }^{a}$ Bienal de São Paulo. Incerteza Viva. São Paulo, 2016.

WHITEHEAD, A. N. Le Concept de Nature. Deuxième édition augmentée. Paris: Librairie Philosophique J. Vrin, 2006.

Recebido em: 30/01/2017. Aprovado em: 10/04/2017. 